\title{
Psychological distress and internet-related behaviors between schoolchildren with and without overweight during the COVID-19 outbreak
}

\author{
Chao-Ying Chen ${ }^{1,2} \cdot$ I-Hua Chen ${ }^{3} \cdot$ Kerry S. O'Brien ${ }^{4} \cdot$ Janet D. Latner ${ }^{5} \cdot$ Chung-Ying Lin $\mathbb{D}^{1,6}$
}

Received: 4 May 2020 / Revised: 29 October 2020 / Accepted: 4 January 2021 / Published online: 25 January 2021

(c) The Author(s), under exclusive licence to Springer Nature Limited 2021

\begin{abstract}
Objective The novel coronavirus disease 2019 (COVID-19) pandemic, and its resulting social policy changes may result in psychological distress among schoolchildren with overweight. This study thus aimed to (1) compare psychological distress (including fear of COVID-19 infection, stress, anxiety, and depression), perceived weight stigma, and problematic internetrelated behaviors between schoolchildren with and without overweight; (2) assess whether perceived weight stigma and problematic internet-related behaviors explained psychological distress.

Methods Schoolchildren ( $n=1357$; mean age $=10.7$ years $)$ with overweight $(n=236)$ and without overweight $(n=1121)$ completed an online survey assessing their fear of COVID-19 infection, stress, anxiety, depression, perceived weight stigma, problematic smartphone application use, problematic social media use, and problematic gaming.

Results Schoolchildren with overweight had significantly higher levels of COVID-19 infection fear, stress, depression, perceived weight stigma, and problematic social media use than those without overweight. Regression models showed that perceived weight stigma and problematic internet-related behaviors were significant predictors of psychological distress among schoolchildren with overweight.

Conclusion Strategies to manage perceived weight stigma and problematic internet-related behaviors may have a positive influence on mental health among schoolchildren with overweight under health-threatening circumstances, such as the current COVID-19 pandemic.
\end{abstract}

Chung-Ying Lin

cylin36933@gmail.com

1 Department of Rehabilitation Sciences, Faculty of Health and Social Sciences, The Hong Kong Polytechnic University, Hung Hom, Hong Kong

2 School of Physical Therapy and Graduate Institute of Rehabilitation Science, College of Medicine, Chang Gung University, Taoyuan, Taiwan

3 School of Education Science, Minnan Normal University, Zhangzhou, China

4 School of Social Sciences, Faculty of Arts, Monash University, Melbourne, VIC, Australia

5 Department of Psychology, University of Hawaii at Manoa, Honolulu, HI, USA

6 Institute of Allied Health Sciences, National Cheng Kung University Hospital, College of Medicine, National Cheng Kung University, Tainan, Taiwan

\section{Introduction}

The rapid growth of novel coronavirus disease 2019 (COVID-19) infection worldwide (>3.4 million COVID-19 infections) has caused more than 230,000 deaths as of May 1,2020 [1]. The absence of an effective treatment means that healthcare providers have paid extensive attention to people who are particularly vulnerable to the COVID-19. This includes those with chronic disease (e.g., diabetes, coronary heart disease), compromised immune systems, and those with overweight (including obesity). Recent studies found that the general population with chronic diseases were vulnerable to greater psychological impact and stress during the outbreak and peak of the COVID-19 pandemic [2, 3]. Patients with overweight may disproportionately develop severe comorbidities following COVID-19 infection [4]. This suggestion is supported by previous work investigating the relationship between influenza and overweight. Specifically, the altered immune response and sedentary lifestyle that influence physiological health contribute to poorer 
clinical outcomes following influenza among patients with overweight [5]. Recent evidence from France found that the severity of COVID-19 infection was positively related to patients' body mass index (BMI). That is, patients with a higher BMI, especially those with a BMI higher than $35 \mathrm{~kg}$ / $\mathrm{m}^{2}$, are more likely to require support from invasive mechanical ventilators [6].

Because of the health consequences mentioned above, people with overweight may additionally suffer from fears about their health and associated psychological distress. Specifically, people with overweight who feel they are more vulnerable to COVID-19-related morbidity and mortality may also display greater psychological distress. Moreover, lifestyle and living patterns have by necessity changed during the COVID-19 outbreak. For example, many governments have implemented social distancing and lockdown laws to prevent expansion of COVID-19 infection [7, 8]. Mainland China had implemented temporary school closures and required primary schoolchildren to study online at home for several months during the COVID-19 outbreak. Such changes in lifestyles may have negative consequence on individuals' mental health. Prior research has shown that major life events, such as the loss of a parent or friend can be associated with psychological distress, and people with overweight can be more vulnerable to such life stressors than their normal-weight counterparts [9]. Accordingly, children with overweight may encounter quite different levels of psychological distress and associated behavioral outcomes due to COVID-19 than children without overweight. Childhood obesity has become a major global epidemic that causes substantial social and health burdens worldwide [10]. Even during pre-pandemic times, children with overweight experience greater psychological distress and impaired psychosocial outcomes due to weight stigma (weight bias) [11]. Due to low body esteem [12], children and adolescents with obesity were more prone to develop depression [13]. In addition to psychological factors, the combination of obesity and stress lead to a reduction in the effectiveness of leptin, a hormone that controls appetite, resulting in further weight gain [14]. Research shows that people with overweight have a higher chance of being bullied and teased than those without overweight [11]. These stigmatizing experiences and the ongoing fear and perception of weight stigma can lead to significant psychological distress [15].

One major lifestyle and behavioral change that has occurred during school closures is increased internet usage by schoolchildren. Schoolchildren are very likely to engage in more internet-related activities for educational, entertainment, and social-engagement purposes during periods of physical distancing and isolation. However, there can be unintended negative consequences if internet behaviors are not monitored or constrained. For example, a prospective cohort study in a healthy adolescent population found more problematic internet use to be associated with higher levels of depressive and anxiety symptoms [16]. Moreover, increased severity of gaming disorder and social media addiction may lead to psychological problems (such as depression, anxiety, and attentional deficits) [17], sleep problems [18], and impaired quality of life [19]. During the unprecedented period of COVID-19 self-isolation and distancing, an increase home-based online activities is likely, and it seems important to examine the relationship between internet-related activities and psychological distress in schoolchildren with overweight during the pandemic.

There is little research examining whether weight status and weight stigma may influence perceptions of vulnerability to infectious diseases, and associated psychological distress; and whether problematic internet-related behaviors during the COVID-19 lockdown are associated with greater fear of COVID-19 infection, and psychological distress. The present study recruited a large sample of schoolchildren with and without overweight from Mainland China to examine the relationships between weight status, weight stigma, problematic internet and social media use, and psychological distress (including fear of COVID-19) during the COVID-19 lockdown.

\section{Methods}

\section{Participants, procedure, and ethical concerns}

The study was part of an ongoing longitudinal project assessing problematic internet-related behaviors among primary school children in third to sixth grades. This research was approved by the ethics committee of the Hong Kong Polytechnic University (IRB ref: HSEARS20190718001). The longitudinal project routinely assesses primary school children's characteristics, problematic internet-related behaviors (smartphone applications, social media, and gaming), perceived weight stigma, and psychological distress across a 1 -year period. During the period of the longitudinal project, the COVID-19 outbreak occurred in Mainland China and the primary schoolchildren were instructed to stay at home for online learning. Consequently, an item on fear of COVID-19 infection was incorporated into the longitudinal project (see "Instruments" section for details) to assess the extent of children's fear related to COVID-19. The present study was cross-sectional, with questionnaire data from the same wave that included and analyzed the COVID-19 question.

The survey was conducted online with the distribution of the survey facilitated by teachers from three primary schools in Sichuan, China. The online survey was generated by the research team and checked by the teachers to ensure that the survey hyperlink worked. Schoolteachers 
then sent the hyperlink to their students for participation. The first page of the online survey stated the objectives and participants' rights, and sought consent from the students and one parent. Following the provision of participation consent from students and one of their parents, access to the survey proper was opened. Eligibility of the primary schoolchildren was defined by the following inclusion criteria (1) they could read and understand the survey, which was written in Chinese and (2) they owned and used at least one smartphone with internet access. The participants were excluded if they misperceived their weight status; that is, their perceived weight status did not fit with their BMI defined weight status. The reason for the exclusion criterion is because prior research shows that misperception of weight status is a strong predictor of children's psychological distress, and we did not wish for this association to confound the present study [20-22].

\section{Measures}

\section{Fear of COVID-19 infection}

Using a visual analog scale (from 0 [not at all afraid] to 10 [completely afraid]), a question "Are you afraid of being infected by COVID-19?" was used to understand to what extent participants fear the COVID-19 infection.

\section{Depression, Anxiety, Stress Scale-21 (DASS-21)}

Using 21 items rated on a four-point Likert scale (ranging from 0 [did not apply to me at all] to 3 [applied to me very much or most of the time]), the DASS-21 assesses three types of psychological distress: stress (seven items), anxiety (seven items), and depression (seven items). Example items for the DASS-21 are "I found it hard to wind down" (for stress), "I was aware of dryness of my mouth" (for anxiety), and "I could not seem to experience any positive feeling at all" (for depression). The item scores are summated in each subscale to indicate the level of psychological distress, where higher scores indicate a higher level of depression, anxiety, or stress. The psychometric properties of the DASS-21 and the Chinese DASS-21 have been found to be good [23, 24]. Moreover, DASS-21 was recently used to assess the mental health of the general population [2, 3], workforce [25], patients with mental illness [26, 27], schoolchildren [28], and healthcare workers [29, 30]. The present study found that the Chinese DASS-21 had good internal consistency $(\alpha=0.82$ for stress subscale; 0.79 for anxiety subscale; and 0.84 for depression subscale).

\section{Perceived weight stigma}

A ten-item measure was used to assess perceived weight stigma. Participants responded to items such as "people act as if you are inferior because of your weight" using a dichotomous scale $(0=$ No and $1=$ Yes $)$. Item scores were summated to indicate the level of perceived weight stigma (scores ranging from 0 to 10 ), with higher scores indicating a higher level of perceived weight stigma. The linguistic validity and internal consistency of the Chinese perceived weight stigma items have been found to be satisfactory [31]. The present study also showed that the Chinese perceived weight stigma items had good internal consistency $(\alpha=0.83)$.

\section{Smartphone Application-Based Addiction Scale (SABAS)}

The six-item SABAS was used to assess level of problematic smartphone application use. The SABAS was designed based on the addiction component model criteria (i.e., salience, mood modification, tolerance, withdrawal conflict, and relapse) proposed by Griffiths [32, 33]. Participants responded to items such as "During the past week, my smartphone is the most important thing in my life" using a Likert scale ranging from 1 (strongly disagree) to 6 (strongly agree). The item scores are summed to indicate the level of problematic smartphone application use, where a higher score indicates a higher level of problematic use. The psychometric properties of the SABAS and the Chinese SABAS have been found to be satisfactory [34-37]. The present study also showed that the Chinese SABAS had good internal consistency $(\alpha=0.88)$.

\section{Bergen Social Media Addiction Scale (BSMAS)}

The BSMAS assesses the level of problematic social media use with six items rated on a five-point Likert scale ranging from 1 (very rarely) to 5 (very often). The scale was developed based on the addiction component model criteria proposed by Griffiths [32,33]. The following is an example item from the BSMAS "How often during the last week have you spent a lot of time thinking about social media or planned use of social media?". Item scores are summated to indicate the level of problematic social media use, where a higher score indicate a higher level of problematic use. The psychometric properties of the BSMAS and Chinese BSMAS have been found to be satisfactory [38-41]. The present study also showed that the Chinese BSMAS had good internal consistency $(\alpha=0.88)$.

\section{Internet Gaming Disorder Scale-Short Form (IGDS9-SF)}

The nine-item IGDS9-SF assesses the level of disordered internet gaming behavior. The scale items were designed based on the nine criteria indicating internet gaming disorder in the "Diagnostic and statistical manual of mental disorders, fifth edition" (DSM-5) [42]. Items such as "During last 
week, do you feel more irritability, anxiety or even sadness when you try to either reduce or stop your gaming activity?" were presented to participants who responded using a fivepoint Likert scale ranging from 1 (never) to 5 (very often). The item scores are summed to indicate the level of problematic gaming, where higher scores indicating higher levels of problematic gaming. The psychometric properties of the IGDS9-SF have been found to be good [43-48]. The present study also showed that the Chinese IGDS9-SF had good internal consistency $(\alpha=0.926)$.

\section{Time spent on internet-related behaviors}

Time spent on internet-related behaviors was assessed with the question: "How much time did you spend on each of the following internet-related behaviors daily?". Participants were asked to indicate time spent on each of the following internet-related behaviors in the past week: smartphone, social media, and gaming. The time spent on each internetrelated behavior was then converted into hours per day in use.

\section{Weight status}

The schoolchildren self-reported their height in $\mathrm{cm}$ and weight in $\mathrm{kg}$. BMI was then calculated to determine whether a schoolchild belongs to a group with overweight or a group without overweight (Table 1) [49]. In addition to reporting height and weight, each schoolchild was asked to report their self-perceived weight status using the question: "What do you think your weight status is?" Answer choices included "Very thin", "Thin", "Normal weight", "Overweight", or "Obese". Then, the self-perceived weight status was reclassified into two categories of "overweight" or "nonoverweight".

Table 1 Body mass index (BMI) cutoffs for weight status according to gender and age.

\begin{tabular}{lll}
\hline Age & \multicolumn{1}{l}{ BMI $\left(\mathrm{kg} / \mathrm{m}^{2}\right)$} & \\
\cline { 2 - 3 } & Boy & Girl \\
\hline 7-7.99 years & 17.0 & 16.4 \\
8-8.99 years & 17.7 & 17.0 \\
9-9.99 years & 18.4 & 17.7 \\
10-10.99 years & 19.4 & 18.4 \\
11-11.99 years & 20.1 & 19.1 \\
12-12.99 years & 21.0 & 20.0 \\
13-13.99 years & 21.9 & 20.9 \\
\hline
\end{tabular}

The cutoffs were calculated based on 2005 Mainland Chinese children at $85 \%$ percentile in BMI. Ref: So et al. [49].

\section{Data analysis}

Independent $t$-tests were used to detect the significant differences between the group with overweight and that without overweight in their psychological distress, perceived weight stigma, problematic internet-related behaviors, and time spent on internet-related behaviors. In addition, multivariate linear regression models were used to examine the associations between psychological distress (i.e., fear of COVID-19 infection, stress, anxiety, and depression), perceived weight stigma, and problematic internet-related behaviors (including problematic smartphone application use, problematic social media use, and problematic gaming). We divided the participants into two groups (participants with overweight and without overweight) to conduct the regression models for each group. Age and gender were adjusted in all the regression models. Moreover, a regression model using all participants (i.e., including those with and without overweight) was used to examine the associations between weight status, psychological distress, perceived weight stigma, and problematic internet-related behaviors. We used the "one in 20 rule" (i.e., one predictor needs 20 participants) in the regression model to determine sufficient sample size. Given that each regression model had six or seven predictors, $120-140$ were deemed sufficient to achieve adequate power. Cohen's $f^{2}$ using the equation of $\frac{R^{2}}{1-R^{2}}$ was calculated to assess the effect size for the regression models. Cohen's $f^{2}$ at 0.02 indicates small effect; 0.15 as medium effect; and 0.35 as large effect. Moreover, all the analyses met their respective assumptions (i.e., normal distribution and variance homogeneity) and were applied using twosided tests.

\section{Results}

Table 2 presents participants' characteristics among schoolchildren with overweight $(n=236 ; 132$ boys; age range $=$ $8-13)$, and without overweight ( $n=1121 ; 557$ boys; age range $=7-14)$, and noneligible participants $(n=657 ; 318$ boys; age range $=7-14$ ). Table 3 shows the means and SDs for psychological distress, perceived weight stigma, problematic internet-related behaviors, and time spent on internetrelated behaviors between the two groups. As can be seen in Table 3, schoolchildren with overweight had significantly higher levels of COVID-19 infection fear, stress, and depression than did those without overweight. Schoolchildren with overweight also had significantly higher levels of perceived weight stigma than did those without overweight. With regard to problematic internet-related behaviors, schoolchildren with overweight had significantly higher levels of problematic social media use than did those without overweight. There were no significant differences between 
Table 2 Participants' characteristics.
Table 3 Comparisons of psychological distress and internet-related behaviors between groups.

\begin{tabular}{lcccc}
\hline & $M(\mathrm{SD})$ or $n(\%)$ & & \multirow{2}{*}{$F$ or $\chi^{2}(p$ value $)$} \\
\cline { 2 - 4 } & Non-OW $n=1121$ & OW $n=236$ & $\begin{array}{l}\text { Noneligible children } \\
n=657\end{array}$ & \\
\hline Age (year) & $10.67(1.11)$ & $10.78(0.93)$ & $10.75(1.06)$ & $1.74(0.18)$ \\
Gender (boy) & $557(49.7 \%)$ & $132(55.9 \%)$ & $318(48.4 \%)$ & $4.04(0.13)$ \\
Height (cm) & $144.47(9.00)$ & $149.80(8.81)$ & $145.20(9.64)$ & $32.95(<0.001)^{* * *}$ \\
Weight (kg) & $35.94(10.51)$ & $58.88(22.33)$ & $51.66(19.06)$ & $342.52(<0.001)^{* * * *}$ \\
$\begin{array}{l}\text { Body mass index } \\
\left.\text { (kg/m }{ }^{2}\right)\end{array}$ & $17.09(4.11)$ & $26.02(8.90)$ & $24.35(8.08)$ & $374.95(<0.001)^{* * *}$ \\
Ethnicity (Han) & $1106(98.7 \%)$ & $235(99.6 \%)$ & $647(98.5 \%)$ & $1.69(0.43)$ \\
Currently ill (yes) & $18(1.6 \%)$ & $6(2.5 \%)$ & $7(1.1 \%)$ & $2.57(0.28)$ \\
\hline
\end{tabular}

Non- $O W$ group with nonoverweight, $O W$ group with overweight.

$* * * p<0.001$.

${ }^{a}$ Noneligible children were those who misperceived their weight status; 123 perceived themselves overweight but were classified as nonoverweight according to body mass index; 534 perceived themselves as nonoverweight but were classified as overweight according to body mass index.

${ }^{\text {b}}$ Currently ill was assessed using a dichotomous item "In the past week, were you ill [e.g., catching a cold or having diarrhea]?".

\begin{tabular}{lrrl}
\hline & \multicolumn{1}{l}{$M(\mathrm{SD}) / n$} & \multirow{2}{*}{$t(p$ value $)$} \\
\cline { 2 - 3 } & \multicolumn{1}{l}{ Non-OW } & \multicolumn{1}{c}{ OW } & \\
\hline Fear of COVID-19 infection & $4.00(3.64) / 1042$ & $5.08(9.03) / 210$ & $2.87(0.004)^{* *}$ \\
Stress & $9.00(2.77) / 1121$ & $9.61(3.04) / 236$ & $2.85(0.005)^{* *}$ \\
Anxiety & $8.15(2.12) / 1121$ & $8.39(2.07) / 236$ & $1.58(0.12)$ \\
Depression & $8.26(2.42) / 1121$ & $8.62(2.61) / 236$ & $1.97(0.049)^{*}$ \\
Perceived weight stigma & $0.92(1.78) / 1121$ & $1.30(2.12) / 236$ & $2.59(0.01)^{*}$ \\
Problematic smartphone application use & $12.43(6.17) / 1121$ & $12.77(6.25) / 236$ & $0.78(0.44)$ \\
Problematic social media use & $8.90(3.81) / 1121$ & $9.61(4.12) / 236$ & $2.56(0.01)^{*}$ \\
Problematic gaming & $12.82(5.41) / 1121$ & $13.10(5.49) / 236$ & $0.72(0.47)$ \\
Time spent on smartphone & $2.29(2.60) / 1121$ & $2.57(2.78) / 236$ & $1.48(0.14)$ \\
Time spent on social media & $1.11(2.03) / 1121$ & $1.20(1.65) / 236$ & $0.65(0.52)$ \\
Time spent gaming & $0.92(2.00) / 1121$ & $1.02(1.95) / 236$ & $0.72(0.47)$ \\
\hline
\end{tabular}

Non- $O W$ group with nonoverweight, $O W$ group with overweight.

$* p<0.05 ; * * p<0.01$.

overweight and nonoverweight in time spent on internetrelated behaviors.

Regression models for schoolchildren without overweight (Table 4) indicated that perceived weight stigma was a significant predictor in models, with higher levels of weight stigma associated with greater fear of COVID-19 infection, and higher levels of stress, anxiety, and depression. Problematic smartphone, social media, and gaming use were also all significant positive predictor in stress, anxiety, and depression, but not COVID-19 fear. Moreover, the regression models for schoolchildren without overweight had small to large effects $\left(f^{2}=0.031-0.504\right)$.

Regression models for schoolchildren with overweight (Table 4) indicated that perceived weight stigma was a significant predictor in fear of COVID-19 infection at the $p<0.10$ level $(p=0.059)$, but not at the conventional 0.05 level. Weight stigma was a significant predictor of stress, anxiety, and depression. With higher levels of weight stigma associated with higher levels of stress, anxiety, and depression. Similar to nonoverweight, problematic smartphone and social media application use were also significant positive predictor in stress, anxiety, and depression, but not fear of COVID-19 infection. Problematic gaming was not a significant predictor of COVID-19 infection fear, but was a significant predictor of stress, and only reached the 0.10 level of significance for anxiety $(p=0.077)$ and depression $(p=0.093)$. Moreover, the regression models for schoolchildren with overweight had small to large effects $\left(f^{2}=0.049-0.821\right)$.

Regression models for schoolchildren regardless of weight status (Table 4) indicated that overweight was a significant 
Table 4 Regression models investigating relationships between internet-related behaviors and psychological distress among children with or without overweight.

\begin{tabular}{|c|c|c|c|c|}
\hline & \multicolumn{4}{|c|}{ Coefficient (SE)/Standardized coefficient } \\
\hline & Fear of COVID infection & Stress & Anxiety & Depression \\
\hline \multicolumn{5}{|l|}{ Group without overweight } \\
\hline Age & $-0.016(0.101) /-0.005$ & $-0.033(0.061) /-0.013$ & $0.017(0.048) / 0.009$ & $-0.072(0.055) /-0.033$ \\
\hline Gender (Ref: boys) & $-0.372(0.229) /-0.051$ & $-0.141(0.139) /-0.025$ & $0.116(0.109) / 0.027$ & $-0.089(0.124) /-0.018$ \\
\hline Perceived weight stigma & $0.279(0.065) / 0.138 * * *$ & $0.426(0.040) / 0.274 * * *$ & $0.382(0.032) / 0.320 * * *$ & $0.398(0.036) / 0.293 * * *$ \\
\hline PSAU & $-0.010(0.027) /-0.017$ & $0.101(0.017) / 0.226 * * *$ & $0.032(0.013) / 0.092^{*}$ & $0.044(0.015) / 0.113^{* *}$ \\
\hline PSMU & $0.050(0.04) / 0.052$ & $0.068(0.024) / 0.094 * *$ & $0.049(0.019) / 0.088 * *$ & $0.085(0.022) / 0.134 * * *$ \\
\hline PG & $0.018(0.031) / 0.027$ & $0.086(0.019) / 0.168 * * *$ & $0.086(0.015) / 0.221 * * *$ & $0.087(0.017) / 0.194 * * *$ \\
\hline$R^{2}$ (Adj. $\left.R^{2}\right)$ & $0.030(0.024)$ & $0.335(0.331)$ & $0.298(0.294)$ & $0.307(0.303)$ \\
\hline Cohen's $f^{2}$ & 0.031 & 0.504 & 0.425 & 0.443 \\
\hline \multicolumn{5}{|l|}{ Group with overweight } \\
\hline Age & $0.485(0.668) / 0.050$ & $-0.370(0.161) /-0.113^{*}$ & $-0.143(0.114) /-0.064$ & $-0.303(0.144) /-0.108^{*}$ \\
\hline Gender & $-1.798(1.291) /-0.099$ & $0.014(0.311) / 0.002$ & $0.062(0.219) / 0.015$ & $0.021(0.277) / 0.004$ \\
\hline Perceived weight stigma & $0.592(0.312) / 0.141^{\#}$ & $0.346(0.077) / 0.241 * * *$ & $0.345(0.054) / 0.353^{* * *}$ & $0.442(0.068) / 0.359 * * *$ \\
\hline PSAU & $-0.093(0.150) /-0.618$ & $0.178(0.036) / 0.362 * * *$ & $0.107(0.026) / 0.323^{* * *}$ & $0.129(0.032) / 0.309 * * *$ \\
\hline PSMU & $-0.232(0.213) /-0.106$ & $0.287(0.053) / 0.388 * * *$ & $0.130(0.037) / 0.259 * * *$ & $0.157(0.047) / 0.248 * * *$ \\
\hline PG & $0.286(0.182) / 0.175$ & $-0.115(0.044) /-0.208^{* *}$ & $-0.055(0.031) /-0.147^{\#}$ & $-0.067(0.039) /-0.140^{\#}$ \\
\hline$R^{2}\left(\operatorname{Adj} . R^{2}\right)$ & $0.047(0.019)$ & $0.451(0.436)$ & $0.410(0.394)$ & $0.404(0.388)$ \\
\hline Cohen's $f^{2}$ & 0.049 & 0.821 & 0.695 & 0.678 \\
\hline \multicolumn{5}{|l|}{ All participants } \\
\hline Weight (Ref: nonoverweight) & $0.297(0.125) / 0.067^{*}$ & $0.108(0.055) / 0.043^{\#}$ & $0.008(0.042) / 0.004$ & $0.035(0.049) / 0.016$ \\
\hline Age & $0.024(0.128) / 0.005$ & $-0.068(0.058) /-0.026$ & $0.003(0.044) / 0.002$ & $-0.094(0.051) /-0.042$ \\
\hline Gender (Ref: boys) & $-0.615(0.286) /-0.062^{*}$ & $-0.097(0.128) /-0.017$ & $0.121(0.098) / 0.029$ & $-0.056(0.113) /-0.011$ \\
\hline Perceived weight stigma & $0.326(0.079) / 0.122 * * *$ & $0.420(0.036) / 0.275 * * *$ & $0.377(0.027) / 0.330 * * *$ & $0.412(0.032) / 0.310 * * *$ \\
\hline PSAU & $-0.021(0.034) /-0.027$ & $0.113(0.015) / 0.246 * * *$ & $0.044(0.012) / 0.129 * * *$ & $0.058(0.013) / 0.145^{* * *}$ \\
\hline PSMU & $0.008(0.049) / 0.007$ & $0.105(0.022) / 0.143 * * *$ & $0.061(0.017) / 0.112 * * *$ & $0.097(0.020) / 0.154 * * *$ \\
\hline PG & $0.057(0.039) / 0.062$ & $0.055(0.018) / 0.105^{* *}$ & $0.064(0.014) / 0.165^{* * *}$ & $0.062(0.016) / 0.138 * * *$ \\
\hline$R^{2}\left(\operatorname{Adj} . R^{2}\right)$ & $0.032(0.026)$ & $0.348(0.344)$ & $0.309(0.305)$ & $0.320(0.316)$ \\
\hline Cohen's $f^{2}$ & 0.033 & 0.534 & 0.447 & 0.471 \\
\hline
\end{tabular}

$P S A U$ problematic smartphone application use, $P S M U$ problematic social media use, $P G$ problematic gaming.

${ }^{\#} p<0.1 ; * p<0.05 ; * * p<0.01 ; * * * p<0.001$.

predictor in fear of COVID-19 infection. Weight stigma was a significant predictor of all types of psychological distress. With higher levels of weight stigma associated with higher levels of fear of COVID-19 infection, stress, anxiety, and depression. Additionally, problematic smartphone, social media, and gaming use were also all significant positive predictor in stress, anxiety, and depression, but not COVID-19 fear. Moreover, the regression models for schoolchildren regardless of weight status had small to large effects $\left(f^{2}=0.033-0.534\right)$.

\section{Discussion}

Consistent with previous findings [11, 20-22], the present study found that schoolchildren with overweight had higher levels of psychological distress and perceived weight stigma than their normal-weight counterparts. Moreover, schoolchildren with overweight had greater problematic social media use than did those without overweight. Regression models indicated that greater perceived weight stigma was associated with greater psychological distress in schoolchildren regardless of their weight status. Moreover, problematic smartphone application use and problematic social media use were associated schoolchildren's stress, anxiety, and depression, regardless of their weight status. Among schoolchildren without overweight, problematic gaming was associated with higher levels of stress, anxiety, and depression, which is in line with previous findings [16, 50]. However, among children with overweight, problematic gaming was associated with lower levels of stress, anxiety, 
and depression. With the small to large effects (and most had large effects) shown by the Cohen's $f^{2}$, the regression models conducted in the present study were generally supported with strong magnitude.

Surprisingly, problematic gaming seemed to be a protective factor against psychological distress in overweight schoolchildren. Specifically, increased problematic use of gaming was significantly associated with less stress, anxiety, and depression. It is possible that the hiding of one's identity (i.e., without revealing real information) during gaming may ease psychological distress for overweight schoolchildren. Unlike gaming, social media usually requires revealing some personal information, such as photographs, and may expose the user's weight status. Thus, for overweight schoolchildren who suffered from weight stigma, anonymous gaming could be an anxietyalleviating activity, which may possibly override the more typical negative influence of problematic online behaviors on psychological well-being [18]. Moreover, gaming does not offer a platform for sharing COVID-19-related information while social media does. Considering the potential impact of COVID-19 on psychological distress, gaming engagement may protect overweight schoolchildren. Future research might explore the potential benefits of certain gaming activities in specific populations.

However, unlike problematic gaming, problematic social media use among overweight children requires additional attention during prolonged school suspension after COVID19 outbreaks. Addiction to or prolonged use of social media has been found to be a great risk of overweight [51, 52]. People with overweight and resultant stigmatizing experiences may be more likely to use social media for virtual interaction instead of real interpersonal activities, and they might be more avoidant of live social interactions, possibly due to anxiety or fear of stigma. They may also heavily rely on social media to search information relating to overweight, which may increase the risk of problematic internet use [53, 54]. Therefore, overweight schoolchildren might heavily depend on social media because they want to search for COVID-19-related information and seek emotional support during the current pandemic period. Unfortunately, such dependence on social media, even when not significantly increasing the time spent on social media, may trigger the development of psychological distress, especially for overweight schoolchildren in the present study.

Due to the policy of lockdown to control COVID-19 outbreak, schoolchildren dramatically increased their internet use to adapt to their study or emotional needs during this period. Therefore, "problematic" use of internet-related behaviors may not be identical to the problematic internet use assessed in pre-COVID-19 studies. That is, problematic internet use should not be defined using the length of internet use and may need to be reframed during the
COVID-19 pandemic. Therefore, the use of standardized instruments (SABAS, BSMAS, and IGDS9-SF) in the present study seems to be appropriate. Specifically, the standardized instruments do not use length of internet use to quantify problematic use; instead, they adopt wellestablished theories (i.e., addiction component model $[32,33]$ and the IGD criteria in the DSM-5 [42]) to reflect problematic use.

Regarding higher psychological distress in schoolchildren with overweight than their peers without overweight, one of the major reasons might be because of the perceived weight stigma in this population. This speculation is supported by the recent meta-analysis conclusion that perceived weight stigma is significantly associated with depression and anxiety in people with overweight [15]. Apart from perceived weight stigma, schoolchildren with overweight might be afraid of the serious health outcomes resulting from COVID-19 infection [6]. In the present study, schoolchildren with overweight demonstrated more fear of being affected by COVID-19 than did those without overweight. However, the present study did not investigate specific reasons why they fear COVID-19 infection. Therefore, the speculation of fearing serious health outcomes resulted from COVID-19 infection needs corroboration from future studies. Moreover, the present study revealed that problematic social media use was more severe in schoolchildren with overweight than those without overweight. Thus, the higher level of psychological distress may come from a greater level of problematic social media use, as prior evidence showed a positive association between psychological distress and problematic social media use [18].

In our results, perceived weight stigma was an important factor contributing to psychological distress, regardless of weight status. Children with high perceived weight stigma might fear that they will not receive high quality health care should they get COVID-19. However, because weight stigma is closely associated with anxiety and depression, the association of weight stigma with fear of COVID infection may simply reflect higher anxiety and poorer mood in those who are stigmatized. Interestingly, the association between perceived weight stigma and the fear of COVID-19 infection was significant in schoolchildren without overweight but only significant at the 0.10 level in those with overweight. The relationship between perceived weight stigma and fear of COVID-19 infection among schoolchildren without overweight is in line with prior evidence showing associations between weight stigma and psychological distress among individuals without overweight [55]. Telephone-based cognitive behavioral therapy could help in the reduction of binge eating and the maintenance of weight loss, and its effectiveness should be evaluated during COVID-19 [56]. 
There are some limitations in the present study. First, all the data including demographics (e.g., body weight and height), psychological constructs, perceived weight stigma, and internet-related behaviors are self-reported. Hence, some information may be susceptible to memory-related bias or social desirability bias. Second, the societal perception of discrimination toward people with overweight varies across countries. Therefore, the perceived weight stigma and resulting consequences during this health crisis may also be different. That is to say, the results should be generalized to other populations with caution. Third, some participants might use different devices (e.g., tablet or computer) for internet use; however, this was not assessed in the present study. Thus, internet use might have been underreported. Lastly, some important confounding variables could not be controlled in the present study. Specifically, schoolchildren's screen behaviors are highly associated with their parents' screen behaviors [57, 58]. However, we did not collect information regarding parents' screen use. Furthermore, the socio-economic status of the family was unknown. Children and adolescents with obesity who lived in poverty were deprived of medical services before the COVID-19 pandemic [59]. Recent studies found that financial difficulties may be the reason for resistance to seeking medical help during the COVID-19 pandemic [60].

\section{Conclusion}

In conclusion, schoolchildren with overweight suffered from stress, depression, perceived weight stigma, and fear of COVID-19 infection during the COVID-19 outbreak period. They also demonstrated problematic social media use. Perceived weight stigma was positively associated with fear of COVID-19 infection, while problematic use of social media and smart phones were also correlated with increased psychological distress, regardless of weight status. However, problematic gaming appeared to be associated with protective effects in schoolchildren with overweight. Therefore, strategies to manage perceived weight stigma may have a positive influence on mental health under health-threatening circumstances, such as the current COVID-19 pandemic. Future studies are warranted on the causes, correlates, and amelioration of fears related to public health crises including COVID-19. Finally, it would be important to develop and test the efficacy of psychological support and monitoring programs for internet-related activities among schoolchildren with overweight.

Funding This study was supported in part by a research grant from the Ministry of Science and Technology, Taiwan (MOST109-2327-B006-005).

\section{Compliance with ethical standards}

Conflict of interest The authors declare that they have no conflict of interest.

Publisher's note Springer Nature remains neutral with regard to jurisdictional claims in published maps and institutional affiliations.

\section{References}

1. World Health Organization. Coronavirus disease (COVID-2019): situation report-85. 2020. https://www.who.int/docs/defaultsource/coronaviruse/situation-reports/20200504-covid-19-sitrep105.pdf?sfvrsn=4cdda8af_2. Accessed 5 May 2020.

2. Wang C, Pan R, Wan X, Tan Y, Xu L, Ho CS, et al. Immediate psychological responses and associated factors during the initial stage of the 2019 coronavirus disease (covid-19) epidemic among the general population in China. Int $\mathrm{J}$ Environ Res Public Health.2020;17:1729. https://doi.org/10.3390/ijerph17051729.

3. Wang C, Pan R, Wan X, Tan Y, Xu L, Mclntyre RS, et al. A longitudinal study on the mental health of general population during the COVID-19 epidemic in China. Brain Behav Immun. 2020;87:40-8. https://doi.org/10.1016/j.bbi.2020.04.028.

4. Ryan DH, Ravussin E, Heymsfield S. COVID 19 and the patient with obesity-the editors speak out. Obesity. 2020;28:847 https://doi.org/10.1002/oby.22808.

5. Luzi L, Radaelli MG. Influenza and obesity: its odd relationship and the lessons for COVID-19 pandemic. Acta Diabetol. 2020;57:759-64. https://doi.org/10.1007/s00592-020-01522-8.

6. Simonnet A, Chetboun M, Poissy J, Raverdy V, Noulette J, Duhamel A, et al. High prevalence of obesity in severe acute respiratory syndrome coronavirus-2 (SARS-CoV-2) requiring invasive mechanical ventilation. Obesity. 2020;28:1195-9. https://doi.org/10.1002/oby.22831.

7. Alvarez E. COVID-19 concerns lead to unusual bans in Dallas County. 2020. https://www.wfaa.com/article/news/health/corona virus/covid-19-concerns-lead-to-unusual-bans-in-dallas-county/ 287-a8a50a42-7e86-4094-82a4-6ca5aeb80e5e. Accessed 16 April 2020.

8. Safer at home order for control of COVID-19. California Health and Safety Code $\S 120295$; Los Angeles County Code $\$ 11.02 .080$. 2020. http://publichealth.lacounty.gov/media/Coronavirus/COVID19_SaferAtHome_HealthOfficerOrder_20200319_Signed.pdf. Accessed 16 April 2020.

9. Farhat T. Stigma, obesity and adolescent risk behaviors: current research and future directions. Curr Opin Psychol. 2015;5:56-66. https://doi.org/10.1016/j.copsyc.2015.03.021.

10. Tran BX, Dang KA, Le HT, Ha GH, Nguyen LH, Nguyen TH, et al. Global evolution of obesity research in children and youths: setting priorities for interventions and policies. Obes Facts. 2019;12:137-149. https://doi.org/10.1159/000497121.

11. Puhl RM, Latner JD. Stigma, obesity, and the health of the nation's children. Psychol Bull. 2007;133:557-80. https://doi.org/ 10.1037/0033-2909.133.4.557.

12. Mak KK, Pang JS, Lai CM, Ho RC. Body esteem in Chinese adolescents: effect of gender, age, and weight. J Health Psychol. 2013;18:46-54. https://doi.org/10.1177/1359105312437264.

13. Quek YH, Tam WWS, Zhang MWB, Ho RCM. Exploring the association between childhood and adolescent obesity and depression: a meta-analysis. Obes Rev. 2017;18:742-54. https:// doi.org/10.1111/obr.12535. 
14. Yang JL, Liu X, Jiang H, Pan F, Ho CS, Ho RC. The effects of high-fat-diet combined with chronic unpredictable mild stress on depression-like behavior and Leptin/LepRb in male rats. Sci Rep. 2016;6:35239. https://doi.org/10.1038/srep35239.

15. Alimoradi Z, Golboni F, Griffiths MD, Broström A, Lin CY, Pakpour AH. Weight-related stigma and psychological distress: a systematic review and meta-analysis. Clin Nutr. 2020;39:2001-13. https://doi.org/10.1016/j.clnu.2019.10.016.

16. Thom RP, Bickham DS, Rich M. Internet use, depression, and anxiety in a healthy adolescent population: prospective cohort study. JMIR Mhealth Uhealth. 2018;5:e44. https://doi.org/10. 2196/mental.8471.

17. Ho RC, Zhang MW, Tsang TY, Toh AH, Pan F, Lu Y, et al. The association between internet addiction and psychiatric co-morbidity: a meta-analysis. BMC Psychiatry. 2014;14:183. https://doi. org/10.1186/1471-244X-14-183.

18. Wong HY, Mo HY, Potenza MN, Chan MNM, Lau WM, Chui TK, et al. Relationships between severity of internet gaming disorder, severity of problematic social media use, sleep quality and psychological distress. Int $\mathrm{J}$ Environ Res Public Health. 2020;17:1879.

19. Tran BX, Huong LT, Hinh ND, Nguyen LH, Le BN, Nong VM, et al. A study on the influence of internet addiction and online interpersonal influences on health-related quality of life in young Vietnamese. BMC Public Health. 2017;17:138. https://doi.org/10. 1186/s12889-016-3983-z.

20. Isomaa R, Isomaa AL, Marttunen M, Kaltiala-Heino R, Björkqvist K. Longitudinal concomitants of incorrect weight perception in female and male adolescents. Body Image. 2011;8:58-63.

21. Lin Y-C, Latner JD, Fung XCC, Lin C-Y. Poor health and experiences of being bullied in adolescents: self-perceived overweight and frustration with appearance matter. Obesity. 2018;26:397-404.

22. Ojala K, Tynjala J, Valimaa R, Villberg J, Kannas L. Overweight adolescents' self-perceived weight and weight control behaviour: HBSC Study in Finland 1994-2010. J Obes. 2012;2012:180176.

23. Shaw T, Campbell MA, Runions KC, Zubrick SR. Properties of the DASS-21 in an Australian community adolescent population. J Clin Psychol. 2017;73:879-92.

24. Wang K, Shi H-S, Geng F-L, Zou L-Q, Tan S-P, Wang Y, et al. Cross-cultural validation of the Depression Anxiety Stress Scale-21 in China. Psychol Assess. 2016;28:e88-100.

25. Tan W, Hao F, McIntyre RS, Jiang L, Jiang X, Zhang L, et al. Is returning to work during the COVID-19 pandemic stressful? A study on immediate mental health status and psychoneuroimmunity prevention measures of Chinese workforce. Brain Behav Immun. 2020;87:84-92. https://doi.org/10.1016/j.bbi.2020. 04.055.

26. Hao F, Tan W, Jiang L, Zhang L, Zhao X, Zou Y, et al. Do psychiatric patients experience more psychiatric symptoms during COVID-19 pandemic and lockdown? A case-control study with service and research implications for immunopsychiatry. Brain Behav Immun. 2020;87:100-6. https://doi.org/10.1016/j.bbi.2020. 04.069.

27. Chang K-C, Hou W-L, Pakpour AH, Lin C-Y, Griffiths MD. Psychometric testing of three COVID-19-related scales among people with mental illness. Int J Ment Health Addict. 2020. https://doi.org/10.1007/s11469-020-00361-6.

28. Chen I-H, Chen C-Y, Pakpour AH, Griffiths MD, Lin C-Y. Internet-related behaviors and psychological distress among schoolchildren during COVID-19 school suspension. J Am Acad Child Adolesc Psychiatry. 2020;59:1099-102. https://doi.org/10. 1016/j.jaac.2020.06.007.

29. Chew NWS, Lee GKH, Tan BYQ, Jing M, Goh Y, Ngiam NJH, et al. A multinational, multicentre study on the psychological outcomes and associated physical symptoms amongst healthcare workers during COVID-19 outbreak. Brain Behav Immun. 2020;88:559-65. https://doi.org/10.1016/j.bbi.2020.04.049.

30. Tan BYQ, Chew NWS, Lee GKH, Jing M, Goh Y, Yeo LLL, et al. Psychological impact of the COVID-19 Pandemic on Health Care Workers in Singapore. Ann Intern Med. 2020;173:317-20. https://doi.org/10.7326/M20-1083.

31. Cheng MY, Wang SM, Lam YY, Luk HT, Man YC, Lin CY. The relationships between weight bias, perceived weight stigma, eating behavior and psychological distress among undergraduate students in Hong Kong. J Nerv Ment Dis. 2018;206:705-10.

32. Griffiths MD. Internet addiction-time to be taken seriously? Addict Res. 2000;8:413-8.

33. Griffiths MD. A 'components' model of addiction within a biopsychosocial framework. J Subst Use. 2005;10:191-7.

34. Yam C-W, Pakpour AH, Griffiths MD, Yau W-Y, Lo C-LM, Ng JMT, et al. Psychometric testing of three Chinese online-related addictive behavior instruments among Hong Kong university students. Psychiatr Q. 2019;90:117-28.

35. Csibi S, Griffiths MD, Cook B, Demetrovics Z, Szabo A. The psychometric properties of the Smartphone Application-Based Addiction Scale (SABAS). Int $\mathrm{J}$ Ment Health Addict. 2018;16:393-403.

36. Lin C-Y, Imani V, Broström A, Nilsen P, Fung XCC, Griffiths $\mathrm{MD}$, et al. Smartphone application-based addiction among Iranian adolescents: a psychometric study. Int J Ment Health Addict. 2019;17:765-80.

37. Soraci P, Ferrari A, Urso A, Griffiths MD. Psychometric properties of the Italian version of the Smartphone Application-Based Addiction Scale (SABAS). Int J Ment Health Addict. 2020. https://doi.org/10.1007/s11469-020-00222-2.

38. Bányai F, Zsila Á, Király O, Maraz A, Elekes Z, Griffiths MD, et al. Problematic social media use: results from a large-scale nationally representative adolescent sample. PLoS ONE. 2017;12: e0169839.

39. Chen IH, Strong C, Lin Y-C, Tsai M-C, Leung H, Lin C-Y, et al. Time invariance of three ultra-brief internet-related instruments: Smartphone Application-Based Addiction Scale (SABAS), Bergen Social Media Addiction Scale (BSMAS), and the nine-item Internet Gaming Disorder Scale-Short Form (IGDS-SF9) (Study Part B). Addict Behav. 2020;101:105960.

40. Leung H, Pakpour AH, Strong C, Lin Y-C, Tsai M-C, Griffiths $\mathrm{MD}$, et al. Measurement invariance across young adults from Hong Kong and Taiwan among three internet-related addiction scales: Bergen Social Media Addiction Scale (BSMAS), Smartphone Application-Based Addiction Scale (SABAS), and Internet Gaming Disorder Scale-Short Form (IGDS-SF9) (Study Part A). Addict Behav. 2020;101:105969.

41. Lin C-Y, Broström A, Nilsen P, Griffiths MD, Pakpour AH. Psychometric validation of the Persian Bergen Social Media Addiction Scale using classic test theory and Rasch models. J Behav Addict. 2017;6:620-9.

42. American Psychiatric Association. Diagnostic and statistical manual of mental disorders: DSM-5. 5th ed. Arlington, VA: American Psychiatric Association; 2013.

43. Beranuy M, Machimbarrena JM, Vega MA, Carbonell X, Griffiths MD, Pontes HM, et al. Spanish validation of the Internet Gaming Disorder Scale-Short Form (IGDS9-SF): prevalence and relationship with online gambling and quality of life. Int J Environ Res Public Health. 2020;17:1562.

44. Evren C, Dalbudak E, Topcu M, Kutlu N, Evren B, Pontes HM. Psychometric validation of the Turkish nine-item Internet Gaming Disorder Scale-Short Form (IGDS9-SF). Psychiatry Res. 2018;265:349-54.

45. Monacis L, de Palo V, Griffiths MD, Sinatra M. Validation of the Internet Gaming Disorder Scale-Short Form (IGDS9-SF) in an Italian-speaking sample. J Behav Addict. 2016;5:683-90. 
46. Pontes HM, Griffiths MD. Measuring DSM-5 internet gaming disorder: development and validation of a short psychometric scale. Comput Human Behav. 2015;45:137-43.

47. Pontes HM, Stavropoulos V, Griffiths MD. Measurement invariance of the Internet Gaming Disorder Scale-Short-Form (IGDS9SF) between the United States of America, India and the United Kingdom. Psychiatry Res. 2017;257:472-8.

48. Wu T-Y, Lin C-Y, Årestedt K, Griffiths MD, Broström A, Pakpour AH. Psychometric validation of the Persian nine-item Internet Gaming Disorder Scale-Short Form: does gender and hours spent online gaming affect the interpretations of item descriptions? J Behav Addict. 2017;6:256-63.

49. So HK, Nelson EA, Li AM, Wong EMC, Lau JTF, Guldan GS, et al. Secular changes in height, weight and body mass index in Hong Kong Children. BMC Public Health. 2008;8:320.

50. Pluhar E, Kavanaugh JR, Levinson JA, Rich M. Problematic interactive media use in teens: comorbidities, assessment, and treatment. Psychol Res Behav Manag. 2019;12:447-55. https://doi.org/10.2147/PRBM.S208968.

51. Robinson TN, Banda JA, Hale L, Lu AS, Fleming-Milici F, Calvert SL, et al. Screen media exposure and obesity in children and adolescents. Pediatrics. 2017;140:S97-101.

52. Tsitsika AK, Andrie EK, Psaltopoulou T, Tzavara CK, Sergentanis TN, Ntanasis-Stathopoulos I. Association between problematic internet use, socio-demographic variables and obesity among European adolescents. Eur J Public Health. 2016;26:617-22.

53. Kaewpradub N, Kiatrungrit K, Hongsanguansri S, Pavasuthipaisit C. Association among internet usage, body image and eating behaviors of secondary school students. Shanghai Arch Psychiatry. 2017;29:208-17.

54. Park S, Lee Y. Associations of body weight perception and weight control behaviors with problematic internet use among Korean adolescents. Psychiatry Res. 2017;251:275-80.

55. Lin C-Y, Strong C, Latner JD, Lin Y-C, Tsai M-C, Cheung P. Mediated effects of eating disturbances in the association of perceived weight stigma and emotional distress. Eat Weight Disord. 2020;25:509-18.

56. Zhang MW, Ho RC, Cassin SE, Hawa R, Sockalingam S. Online and smartphone based cognitive behavioral therapy for bariatric surgery patients: initial pilot study. Technol Health Care. 2015;23:737-744. https://doi.org/10.3233/THC-151026.

57. Lin Y-C, Tsai M-C, Strong C, Hsieh Y-P, Lin C-Y, Lee CSC. Exploring mediation roles of child screen-viewing between parental factors and child overweight in Taiwan. Int $\mathbf{J}$ Environ Res Public Health. 2020;17:1878.

58. Lin Y-C, Fung XCC, Tsai M-C, Strong C, Hsieh Y-P, Lin C-Y. Insufficient physical activity and overweight: does caregiver screen-viewing matter? J Child Fam Stud. 2019;28:286-97.

59. Tran BX, Nghiem S, Afoakwah C, Latkin CA, Ha GH, Nguyen $\mathrm{TP}$, et al. Characterizing obesity interventions and treatment for children and youths during 1991-2018. Int J Environ Res Public Health. 2019;16:4227. https://doi.org/10.3390/ijerph16214227.

60. Tran BX, Vu GT, Latkin CA, Pham HQ, Phan HT, Le HT, et al. Characterize health and economic vulnerabilities of workers to control the emergence of COVID-19 in an industrial zone in Vietnam. Saf Sci. 2020;129:104811. https://doi.org/10.1016/j.ssci. 2020.104811. 